\title{
O PAPEL DO ESTADO NO COMBATE AOS ENTORPECENTES: ANÁLISE DO PROGRAMA SAÚDE NA ESCOLA
}

\author{
Márcio Silveira Rodrigues \\ Militar da Marinha do Brasil \\ Graduação em Licenciatura Plena em Pedagogia pelo CEDERJ/UERJ \\ Pós-Graduação em Gestão em Saúde Pública pela UFF \\ Graduando em Licenciatura em Geografia pelo CEDERJ/UERJ \\ $\triangle$ marrodsil@bol.com.br \\ Rosangela Esméria Campos \\ Especialização em Serviço Social pela Universidade Federal Fluminense \\ Estatutário do Tribunal de Justiça do Estado do Rio de Janeiro, Brasil \\ \rosangelaesmeriacampos@yahoo.com.br
}

\begin{abstract}
Resumo:
O presente trabalho tem como foco demonstrar a importância do Programa Saúde na Escola enquanto componente estratégico dos Projetos Políticos Pedagógicos das Unidades de Ensino, que em conjunto com as Secretarias de Saúde dos diversos estados e municípios, visam articular ações que promovam a cidadania e consecução do desenvolvimento pleno do discente em seus vários estágios acadêmicos. Adotando uma metodologia interdisciplinar buscam através de diversos atores da esfera educacional e de saúde, implementar políticas públicas, articulando ações que contribuam para combater, diagnosticar, dirimir, conscientizar e prevenir acerca do uso de substâncias psicoativas lícitas e ilícitas no interior das escolas e também do seu entorno. Outros pontos que são abordados se referem à gravidez não planejada de adolescentes e às doenças sexualmente transmissíveis, haja visto que ambas se constituem num problema de saúde pública e fator preponderante da evasão escolar na atualidade. Por fim, os esforços empregados por todos os integrantes, tanto das áreas gerencial e operacional visam atingir uma maior eficiência possível das ações adotadas e que possam serem observadas quantitativamente e qualitativamente através do estudo dos resultados obtidos, e principalmente, e não menos importante, que possam serem constatadas uma real "metanoia" na vida das crianças e jovens que permeiam o mundo escolar.
\end{abstract}

Palavras-chave: Escola; Saúde; Entorpecentes.

\section{THE ROLE OF THE STATE IN THE FIGHT TO NARCOTICS: A ANALYSIS OF THE PROGRAM "SAÚDE NA ESCOLA" (HEALTH IN SCHOOL)}

\begin{abstract}
:
This work focuses on demonstrating the importance of the Program "Saúde na Escola" (Health in School) as a strategic component of Political Projects Pedagogical of Teaching Units, which together with the Health Departments of the various states and municipalities, aim to articulate actions that promote citizenship and achievement of full development of the student in their various academic stages. Adopting an interdisciplinary methodology seek through various actors in the educational sphere and health, implementing public policies, articulating actions that contribute to combat, diagnose, resolve, raise awareness and prevent about the use of licit and illicit psychoactive substances within schools and also the its
\end{abstract}


surroundings. Other points that are covered refer to unplanned teenage pregnancies and sexually transmitted diseases, given the fact that both constitute a public health problem and a major factor in truancy today. Finally, the efforts made by all members of both the managerial and operational areas aim to achieve highest possible efficiency of the actions taken and can be quantitatively observed and qualitatively by studying the results, and especially, not least, that They can be observed real "metanoia" in the lives of children and young people that permeate the school world.

Keywords: School; Health; Drugs.

\section{EL PAPEL DEL ESTADO EN LA LUCHA DE ESTUPEFACIENTES: ANÁLISIS DEL PROGRAMA "SAÚDE NA ESCOLA" (SALUD EN LA ESCUELA)}

\section{Resumen:}

En este trabajo se centra en demostrar la importancia del Programa "Saúde na Escola" (Salud en la Escuela) como un componente estratégico de los proyectos políticos Pedagógico de Unidades de Enseñanza, que junto con los Departamentos de Salud de los diversos estados y municipios buscan articular acciones de promoción de la ciudadanía y para lograr el pleno desarrollo del alumno en sus diversas etapas académicas. La adopción de una metodología interdisciplinaria buscan a través de diversos actores del ámbito educativo y de la salud, la implementación de políticas públicas, la articulación de acciones que contribuyan a combatir, a diagnosticar, resolver, la sensibilización y la prevención del uso de sustancias psicoactivas lícitas e ilícitas dentro de las escuelas y también sus alrededores. Otros puntos que se discuten se refieren a los embarazos adolescentes no deseados y enfermedades de transmisión sexual, dado el hecho de que ambos constituyen un problema de salud pública y un importante factor de absentismo escolar en la actualidad. Por último, los esfuerzos realizados por todos los miembros de ambas las áreas operativas y de gestión apuntan a lograr mayor eficiencia posible de las acciones llevadas a cabo y puede ser observado cuantitativa y cualitativamente mediante el estudio de los resultados, y sobre todo, no menos importante, que se pueden observar "metanoia" reales en las vidas de los niños y jóvenes que impregnan el mundo de la escuela.

Palabras clave: Escuela; Salud; Drogas.

\section{INTRODUÇÃO}

Segundo BESSA (2004), atualmente, no Brasil grande parte dos jovens já experimentou algum tipo de entorpecente. Levantamento feito em 2012 pelo INPAD (Instituto Nacional de Políticas Públicas do Álcool e outras Drogas), onde foram ouvidas aleatoriamente 4067 pessoas acima de 14 anos, em todo o território nacional, revelou que em 2006 existia menos de um adolescente para cada adulto usuário de maconha, enquanto em 2012 este número subiu de 1,4 adolescentes para cada adulto usuário. Mais de um terço dos usuários adultos foram identificados como dependentes, sendo que mais da metade dos usuários experimentaram maconha pela primeira vez antes dos 18 anos e 17\% revelaram que conseguiram a droga na escola. 
Tendo em vista a disseminação do uso de drogas ilícitas entre adolescentes e jovens, foi criado em 2007 pelo Governo Federal, em parceria com os estados e municípios, o Programa Saúde na Escola, tendo como principal objetivo conscientizar os alunos das consequências do uso de entorpecentes, bem como reduzir o uso destas substâncias naqueles que porventura estivessem fazendo.

Neste viés, o objetivo do presente trabalho é analisar o funcionamento do referido Programa no CIEP 146-Cordelino Teixeira Paulo, pertencente à Rede Estadual de Ensino, localizado na cidade de São Pedro da Aldeia (RJ), com o fim de verificar a sua efetividade.

O trabalho está estruturado em duas partes, a saber: Primeiramente, será feita uma exposição teórica sobre o Programa Saúde na Escola e, posteriormente, uma análise acerca de sua implementação e desenvolvimento no CIEP 146 - Cordelino Teixeira Paulo, em São Pedro da Aldeia (RJ), a partir de pesquisa realizada com diretores, alunos e seus responsáveis.

\section{REFERENCIAL TEÓRICO}

Nas duas últimas décadas do século XX até o presente momento, os trabalhos de prevenção do uso de drogas vêm concentrando as ações na educação e saúde, com valorização da vida e participação da família, mediadas pelo Poder Público.

No Brasil, a partir de 1987, houve aumento do consumo de substâncias psicoativas entre crianças e adolescentes e o percentual de adolescentes no país que já consumiu drogas entre 10 e 12 anos de idade é extremamente significativo: 51,2\% já usaram bebidas alcoólicas; $11 \%$ tabaco; $7,8 \%$ solventes; $2 \%$ ansiolíticos e $1.8 \%$ usaram anfetamínicos. (CARLIN, 2002).

Tal situação é considerada problema de saúde pública, tendo em vista que a droga afeta o indivíduo, a família e a comunidade, com sérias repercussões devido à associação com a violência, os acidentes, a gravidez não programada e as doenças sexualmente transmissíveis, contribuindo, dessa forma, para os quadros de morbidade e mortalidade. (PILLON, 2004). Segundo OLIVEIRA e BITTENCOURT (2008, p.17),

\footnotetext{
“A prevenção, no entanto, é sempre uma atitude de antecipação, de previsão do futuro e a prevenção mais eficaz é aquela em que é possível eliminar as causas. No caso das drogas, as causas do uso e abuso não estão bem estabelecidas e ao longo
} 
dos anos as estratégias de prevenção vêm sendo modificadas em função do contexto sociocultural, dos movimentos sociais e das necessidades de saúde da população"

As ações preventivas devem ser direcionadas às comunidades em situação de risco e aos problemas decorrentes do uso/abuso de drogas. Dentre os fatores de risco relacionados ao uso e abuso de drogas há de se considerar: precárias condições de moradia, presença do tráfico, ausência de perspectivas de trabalho, de ascensão social e de opções de vida socialmente integradoras.

A Resolução n³/GSIPR/CH/CONAD, de 27/10/05, do Conselho Nacional Antidrogas, criou a Política Nacional sobre Drogas, e serviu de base para nortear as diretrizes que levariam à criação do Programa Saúde na Escola (PSE), instituído pelo Decreto Presidencial 6.2286/07, como proposição de uma política intersetorial entre os Ministérios da Educação e Saúde, na perspectiva de prevenção, promoção e atenção à saúde de crianças e adolescentes.

BESSA (2004) traça um perfil dos usuários, juntamente com outros especialistas, discutindo o consumo de drogas como um comportamento que pode ser comum, em especial, entre subgrupos expostos a importantes fatores de risco (disponibilidade de drogas, baixo custo, o abandono da escolar, família problemática, entre outros). Sob esta ótica, a criação do PSE visa integrar Educação e Saúde, proporcionando melhorias na qualidade de vida da população a partir de um contexto social amplo e com um público-alvo em formação.

Baseado nesta premissa, segundo o documento apresentado pelo Ministério da Saúde, em conjunto com o Ministério da Educação, as orientações sobre o Programa Saúde na Escola para a Elaboração dos Projetos Locais tem como objetivo apresentar aos profissionais e gestores de saúde pública e educação pública a proposição desta política de combate e prevenção às drogas, contando para isso com a colaboração e parceria entre os Estados e Municípios, considerando as peculiaridades de cada localidade e sua cultura local, respeitando os diferentes contextos sociais e saberes informais, a fim de que as propostas sugeridas façam sentido e sejam realmente eficazes. 


\section{PROCEDIMENTOS METODOLÓGICOS}

O tipo de pesquisa foi de forma básica, complementada pela aplicada, com enfoque no Programa "Saúde na Escola" de forma abrangente, e tomou por base os levantamentos feitos pelo INPAD (Instituto Nacional de Políticas Públicas do Álcool e Outras Drogas), as Orientações sobre o Programa Saúde na Escola.

A abordagem do problema foi efetuada através de pesquisa qualitativa, complementada por pesquisa bibliográfica para obtenção das opiniões de diversos autores sobre o tema abordado. Serão aplicados questionários junto a diretores, alunos e responsáveis que participam do projeto no CIEP 146 -Cordelino Teixeira Paulo ${ }^{1}$, localizado no município de São Pedro da Aldeia (RJ), com a finalidade de ouvir suas impressões sobre o referido Programa e a partir daí, examinar a sua efetividade. Para tal, foram entrevistados 2 diretores e, aleatoriamente, 90 alunos e 90 responsáveis pelos alunos.

As pesquisas foram feitas na escola durante as aulas de Ensino Religioso, onde estava sendo abordados temas interdisciplinares, entre eles a prevenção ao uso de drogas. As entrevistas foram feitas nos meses de fevereiro e março de 2015.

\section{DESENVOLVIMENTO}

O Programa Saúde na Escola foi instituído pelo Decreto Presidencial 6286, de 5 de dezembro de 2007, como uma política que abrangesse os âmbitos dos Ministérios da Saúde e Educação, num esforço que exigia atenção de forma integral à saúde de crianças, adolescentes e jovens do Ensino Público Básico².

As ações deste Programa possuem uma estrutura operacional que se inicia considerando o contexto escolar e social do público alvo, através do diagnóstico local e capacidade operativa deste mesmo público, composto pelos alunos e comunidade escolar.

\footnotetext{
${ }^{1}$ A escola em questão foi escolhida por se localizar no centro da cidade e atender a uma clientela variada, bem como apresentar um número expressivo de alunos com problemas de uso de entorpecentes, segundo relatos da direção e do corpo docente da unidade escolar.

2 A educação básica ou ensino básico é o nível de ensino correspondente aos primeiros anos de educação escolar ou formal. Esta denominação corresponde, consoante o sistema educativo que o ministra, a um conjunto específico de anos de escolaridade, correspondendo, na generalidade dos casos, aos primeiros quatro a nove anos.
} 
O Programa Saúde na Escola (PSE) é implantado por meio de adesão dos municípios que tiverem desenvolvido equipes de Saúde da Família, compostas de médicos, nutricionistas, enfermeiras e psicólogos conforme as normas preconizadas pela Política Nacional de Atenção Básica, articulados com os Estados e o Distrito Federal. A eficácia deste programa se baseia efetivamente no compromisso e interação entre as esferas governamentais, aliando Saúde e Educação.

Partindo da premissa de que cada localidade possui suas particularidades culturais, as práticas de saúde na escola consideram os inúmeros contextos sociais em que são inseridos, com atenção devida para os saberes formais e sem desconsiderar os saberes populares, de forma que estas práticas propostas façam sentido para todos os envolvidos. Assim, é importante que todos os segmentos da comunidade escolar, juntamente com os profissionais de saúde, estejam envolvidos na construção e execução PSE, a fim de que as ações na escola sejam devidamente acopladas no Projeto Político Pedagógico (PPP) da mesma, conforme prevê a Portaria 1861, de 4 de setembro de 2008, sancionada pelo Ministério da Saúde.

As equipes de saúde do município, compostas de agentes comunitários de saúde, médicos, enfermeiros, dentistas e nutricionistas trabalham de modo interdisciplinar nas unidades de ensino, com ênfase em diversas ações que vão desde a prevenção de doenças e a assistência às unidades de ensino para auxiliar nesta área até a prevenção e conscientização sobre o uso de entorpecentes, em consonância com os profissionais da educação presentes na unidade escolar.

As diretrizes para a implementação do PSE são:

I-Descentralização e respeito à autonomia federativa;

II-Integração e articulação das redes públicas de ensino e saúde;

III-Territorialidade;

IV-Interdisciplinaridade e intersetorialidade;

V-Integralidade;

VI-Cuidado ao longo do tempo;

VII-Controle social

VIII-Monitoramento e avaliação permanente

(Orientações sobre o PSE para Elaboração de Projetos Locais - Ministérios da Saúde e Educação) 
Seus principais objetivos são: promover a saúde; articular as ações do Sistema Único de Saúde (SUS) e das redes de Educação Básica Pública; contribuir para a constituição de condições para a formação integral dos educandos; contribuir para a construção de um sistema de atenção social, focado na promoção da cidadania e dos direitos humanos; fortalecer o enfrentamento das vulnerabilidades, no campo da saúde, que possam comprometer o pleno desenvolvimento escolar; promover a comunicação entre escola, comunidade e unidades de saúde, com a finalidade de assegurar a troca de informações sobre as condições de saúde dos estudantes e fortalecer a participação comunitária nas políticas de Educação Básica e Saúde, dentro das três esferas governamentais.

De posse destas determinações, o Ministério da Educação instituiu o Programa Mais Educação (PDE), cuja proposta amplia a jornada de estudo dos educandos e promove o conceito de Educação Integral, num modelo que focaliza o sujeito em busca do desenvolvimento de todas as suas potencialidades, equilibrando todos os diferentes aspectos cognitivos, afetivos e sociais, sendo este um instrumento que atua juntamente com o PSE para atender a demanda integral de crianças e adolescentes.

A implementação do Programa Saúde na Escola prevê diversas ações, tais como: palestras, oficinas de artesanato, eventos esportivos, distribuição de preservativos, que devem ocorrer de forma simultânea, por isso as mesmas são apresentadas por componentes ou áreas temáticas, a saber: 1) Avaliação Clínica e Psicossocial, onde as condições de saúde dos alunos são avaliadas; 2) Ações de Promoção da Saúde e Prevenção de doenças e agravos, onde se destacam as palestras sobre alimentação saudável, saúde sexual e reprodutiva, prevenção ao uso do álcool, tabaco e outras drogas, 3) Promoção da Cultura de Paz e prevenção das violências e acidentes. ${ }^{3}$

A gestão deste serviço é descentralizada, podendo ser constituída por grupos de trabalho e/ou grupos gestores, nas três esferas governamentais, contando também com a participação de organizações da sociedade civil e outros parceiros locais, sendo que cada grupo de trabalho pode construir projetos originais junto às escolas participantes do PSE, mas

\footnotetext{
${ }^{3}$ Fonte: Ministério da Saúde e Ministério da Educação Orientações sobre o Programa Saúde na Escola para a elaboração dos Projetos Locais
} 
também podem incorporar iniciativas que já estejam em curso e solicitar a implementação de projetos oficiais.

A capacitação de todos os envolvidos no Programa é feita de diferentes formas, tanto de modo presencial como à distância, através de cursos de formação continuada para professores, gestores de educação básica e profissionais das equipes de Saúde na Família dos municípios que aderem ao PSE, atendendo a demanda nacional ou regional, através da Secretaria de Educação, UAB (Universidade Aberta do Brasil) e Polos de Multiplicação, que consistem em locais onde aqueles profissionais que foram capacitados, sejam da área de saúde ou educação, vão repassar estes conhecimentos para os demais profissionais, multiplicando assim o conhecimento adquirido.

Os Ministérios da Saúde e Educação, em parceria com as entidades e associações representativas das Secretarias estaduais e municipais, analisam os indicadores do Programa Saúde na Escola e, após a verificação de sua eficácia ou não, reformulam as ações a fim de atingir o maior público-alvo possível.

Atualmente, 4684 municípios possuem parceria com o Governo Federal para o desenvolvimento do Programa Saúde na Escola. ${ }^{4}$ Para aderir ao Programa, cada município tem 90 dias a contar da intenção de adesão ao referido Programa para formalizar a mesma, por meio de envio de documentos oficiais, por meio eletrônico e ofícios ao Governo Federal, bem como a elaboração de um Grupo de Trabalho Intersetorial, onde é necessária a presença de pelo menos um membro representante das Secretarias de Educação e Saúde, a fim de que seja garantida a eficácia da cobertura das escolas, numa proporção de $100 \%$ da proposta inicial.

No projeto local de criação do PSE deve constar:

- Diagnóstico situacional, que possibilitará a compreensão sobre o cenário educacional local;

- Mapeamento da rede SUS e educacional, para que sejam criados espaços comuns, denominados "territórios de responsabilidade";

\footnotetext{
${ }^{4}$ Fonte: www.mds.gov.br/bolsafamilia/informes/.../informe-gestores-no-42
} 
- Atribuiçõoes da esfera municipal e das escolas, quantificando o número de escolas em cada unidade e suas questões prioritárias, bem como definição dos responsáveis das áreas de saúde e educação, dentro de cada segmento do projeto e seus territórios de atuação;

- Identificação de cada instituição de ensino atendida pelo programa, com a definição do professor responsável pelas ações de articulação, prevenção e promoção de saúde na escola.

- Elaboração de um Plano de Ação com atividades do PSE que serão inseridas no PPP de cada uma das unidades de ensino.

\section{RESULTADOS}

A escola escolhida para ser objeto de estudo foi o CIEP BRIZOLÃO 146 - Professor Cordelino Teixeira Paulo, localizado no município de São Pedro da Aldeia, RJ, pertence à rede estadual de ensino. A referida escola possui atualmente 904 alunos matriculados oficialmente nas modalidades de ensino fundamental (anos finais) e ensino médio. A escola situa-se na zona urbana do município e possui dois diretores, 44 professores regentes, 25 funcionários técnico-administrativos e 15 de apoio. Conta com biblioteca, laboratório de informática e quadra de esportes, cujos espaços de área comum são característicos do projeto original dos CIEPs 5 .

A escola funciona em dois turnos (manhã e tarde). No prédio também funciona o Núcleo de Tecnologia Educacional (NTE), que promove cursos de capacitação digital para professores multiplicadores e alunos do Curso Normal e o Centro de Estudos para Jovens e Adultos (CEJA), que proporciona a jovens e adultos que estavam fora da escola na idade correta à oportunidade de concluir os estudos através da modalidade semipresencial.

Com o fechamento dos Núcleos de Saúde, que eram responsabilidade do Governo Estadual, a partir de 2007, a Prefeitura Municipal de São Pedro da Aldeia estabeleceu uma parceria com o Governo do Estado, oferecendo aos alunos da rede estadual o mesmo tratamento dispensado aos alunos da rede municipal de ensino e que continua até hoje, através

\footnotetext{
${ }^{5} \mathrm{O}$ projeto pedagógico do professor Darcy Ribeiro, quando de sua implantação, tinha por objetivo proporcionar aos alunos uma Educação em tempo integral, no qual o aluno teria supridas todas as suas necessidades educacionais, entre elas aquelas que se referiam à saúde. Assim, estava previsto que cada CIEP contaria com uma equipe de saúde composta por pediatras, enfermeiros e dentistas. Fonte: http://pmspa.rj.gov.br
} 
dos Núcleos de Saúde Escolar, com ações promovidas pelo Programa Saúde na Escola, onde a comunidade escolar recebe visitas semanais de médicos e dentistas, bem como são efetuados a distribuição de remédios para a população que visita estes postos.

Na primeira fase de implantação foi realizado um estudo exploratório no qual as diretoras apontaram como principais problemas o uso de drogas e a gravidez na adolescência, o que levantou as ações que realmente poderiam ser postas em prática, em consonância com a construção do Projeto Político Pedagógico da escola, cujo tema central era a construção da cidadania. Após o diagnóstico inicial, foram promovidas ações de prevenção ao uso de entorpecentes e utilização de métodos anticoncepcionais entre as alunas com vida sexual ativa comprovada. Depois de 8 meses de implantação, o número de adolescentes atendidos pelo Programa já ultrapassava a previsão inicial de $30 \%$ da comunidade escolar ${ }^{6}$.

Para poder mensurar as opiniões sobre a efetividade do Programa na unidade escolar, foram escolhidos aleatoriamente 90 alunos das turmas de ensino médio dos dois turnos, 90 responsáveis e duas diretoras, aos quais foram aplicados questionários, sendo que no final foram devolvidos 60 questionários preenchidos pelos alunos, 75 preenchidos pelos responsáveis dos alunos e 02 questionários preenchidos pelas diretoras. Os resultados podem ser observados nas tabelas 1,2 e 3 .

Tabela 1. Opinião dos alunos sobre o Programa Saúde na Escola

\begin{tabular}{lccc}
\hline \multicolumn{1}{c}{ ITEM PESQUISADO } & \multicolumn{3}{c}{ AVALIAÇÃO } \\
\hline Bntendimento sobre o programa Saúde na Escola & $80 \%$ & REGULAR & INSUFICIENTE \\
\hline $\begin{array}{l}\text { Opinião sobre os benefícios que o Programa } \\
\text { trouxe }\end{array}$ & $79 \%$ & $14 \%$ & $5 \%$ \\
\hline Nível de interesse na continuidade do Programa & $75 \%$ & $16 \%$ & $7 \%$ \\
\hline Envolvimento com o programa & $74 \%$ & $15 \%$ & $11 \%$ \\
\hline
\end{tabular}

Fonte: Própria.

\footnotetext{
${ }^{6}$ Fonte: http://pmspa.rj.gov.br
} 
Tabela 2. Opinião dos responsáveis pelos alunos sobre o Programa Saúde na Escola

\begin{tabular}{lllc}
\hline \multicolumn{1}{c}{ ITEM PESQUISADO } & & AVALIAÇÃO \\
\hline Entendimento sobre o programa Saúde na Escola & BOM & REGULAR & INSUFICIENTE \\
\hline Opinão sobre os benefícios que o Programa trouxe & $89 \%$ & $25 \%$ & $3 \%$ \\
\hline Nível de interesse na continuidade do Programa & $85 \%$ & $10 \%$ & $5 \%$ \\
\hline
\end{tabular}

Fonte: Própria.

Tabela 3. Opinião dos Diretores sobre o Programa Saúde na Escola

\begin{tabular}{|c|c|c|c|}
\hline \multirow[t]{2}{*}{ ITEM PESQUISADO } & \multicolumn{3}{|c|}{ AVALIAÇÃO } \\
\hline & BOM & REGULAR & INSUFICIENTE \\
\hline Entendimento sobre o programa Saúde na Escola & $90 \%$ & $5 \%$ & $5 \%$ \\
\hline Opinião sobre os benefícios que o Programa trouxe & $89 \%$ & $6 \%$ & $5 \%$ \\
\hline Nível de interesse na continuidade do Programa & $75 \%$ & $16 \%$ & $9 \%$ \\
\hline Envolvimento com o programa & $95 \%$ & $5 \%$ & $0 \%$ \\
\hline
\end{tabular}

Fonte: Própria.

O presente estudo pautou em uma amostra representativa dos adolescentes que frequentam a escola, cursando os últimos anos no ensino fundamental e o ensino médio. Foi usado um questionário aplicado coletivamente em uma sala de aula que, por garantir o anonimato, constitui-se num adequado procedimento para a obtenção de informações sobre comportamentos privados ou ilegais.

Segundo análise da Tabela 1, que representa a pesquisa realizada entre os estudantes, verifica-se que a maior parte dos pesquisados entende e reconhece a importância do PSE em sua escola e o avalia como instrumento efetivo no combate ao uso de entorpecentes. 
A Tabela 2 demonstra a opinião dos responsáveis quanto o PSE. Os números são similares aos obtidos na pesquisa entre os estudantes, sendo que $85 \%$ dos responsáveis consideram o Programa importante.

$\mathrm{Na}$ Tabela 3, que demonstra a visão das diretoras da escola, fica claro que elas acreditam na efetividade do Programa, uma vez que consideram o papel do Poder Público, através da Saúde, um importante aliado no processo de formação de ensino e aprendizagem dos alunos, bem como no fortalecimento de laços com a comunidade escolar.

Deve-se ressaltar que os dados do presente estudo se referem à amostra de adolescentes no âmbito escolar e não podem ser extrapolados para a população geral de adolescentes. Contudo, tendo em vista que quase toda a população passa pela escola em idade e circunstâncias bastante favoráveis à assimilação de novos hábitos e conhecimentos, a escola torna-se um espaço privilegiado para o desenvolvimento de programas preventivos, sendo recomendável o estabelecimento de políticas neste sentido.

Analisando os dados obtidos foi possível observar que alguns alunos, embora tenham participação ativa no Programa, em alguns momentos, sentem impelidos a experimentar algum tipo de droga, lícita ou ilícita, muitos por pressão dos amigos, outros por curiosidade.

Os dados coletados permitem verificar que o Programa ainda necessita de ajustes para que possa atingir de forma eficaz o público-alvo a que propõe. Algumas ações podem ter efeitos mais diretos entre a população, como a elaboração de um documento de comprometimento assinado pelos pais na escola com o objetivo de supervisionar com mais frequência as atividades dos filhos fora do âmbito escolar e a presença mais constante de médicos na unidade escolar com a finalidade de conscientizar os adolescentes de forma direta sobre os malefícios do uso de entorpecentes, também seria interessante uma parceria maior com a Polícia, com patrulhamento mais eficiente nas escolas e arredores, a fim de inibir a ação de traficantes que rondam as mesmas aliciando os jovens para uso e tráfico de drogas.

Escolas promotoras de saúde têm como objetivo a formação de adultos saudáveis e habilitados a fazer pleno uso de seus potenciais, por isso na visão geral, a comunidade escolar compreende a importância de implementar programas de saúde aliados ao sistema educacional, incentivando um estilo de vida saudável e coibindo o uso de entorpecentes na 
adolescência, pois a utilização destas substâncias a longo prazo pode trazer muitos prejuízos, tanto de ordem social quanto física e psíquica.

\section{CONCLUSÃO}

O Programa Saúde na Escola vem se aprimorando a cada dia, trata-se de uma inciativa inovadora com grande impacto social e que deve possuir uma continuidade em suas práticas, a fim de que a efetividade seja maior.

Observa-se que muitos responsáveis, e até mesmo os próprios alunos, encaram o Programa com certa desconfiança, embora participem do mesmo. Alguns consideram as ações propostas como uma perda de tempo, pois já estão envolvidos com o uso de substâncias ilegais, mas como o aumento do uso de entorpecentes cada vez mais cedo, se faz necessário que a Educação, juntamente com outros parceiros, repense as estratégias de ensino e que as ações educativas em saúde superem as atividades assistencialistas, permitindo assim que os alunos adotem comportamentos e estilos de vida mais saudáveis.

Comparando-se a o estudo com os questionários aplicados, foi possível observar o quanto os responsáveis dos alunos pesquisados acreditam na importância do Programa Saúde na Escola quanto à informação e conscientização frente ao uso de entorpecentes. Entretanto, esperam uma ação mais ostensiva, de maneira que alcance um percentual maior de jovens sobre os malefícios que advém do uso de drogas e entorpecentes, além do investimento em outras frentes, de forma que os jovens possam se manter mais tempo ocupados e menos tempo ociosos. 


\section{REFERÊNCIAS}

BESSA, M. A. Adolescência e drogas .2004 São Paulo: Ed. Contexto.

BRASIL. Instituto Nacional de Ciência e Tecnologia para Políticas Públicas do Álcool e outras Drogas (INPAD). Dados sobre o uso de álcool e outras drogas no Brasil. 2012. Disponível em: <www.sesipr.org.br>cuide-semais>alcooleoutrasdrogas > . Acesso em: 14/02/15.

BRASIL. Ministério da Educação. PROJETO SAÚdE E PREVENÇÃO NAS ESCOLAS. 2009. Disponível em < http://portal.mec.gov.br/projeto-saude-e-prevencao-nas-escolas-spe/apresentacao > Acesso em 12/01/15

BRASIL. Ministério da Saúde. CADERNOS DE ATENÇÃO BÁSICA. 2009.Disponível em: <http://189.28.128.100/dab/docs/portaldab/publicacoes/caderno_34.pdf > Acesso em 10/01/15.

CARLINI E.A; GALDURÓZ F.C.J; NAPPO A.N; NOTO A.R. I Levantamento domiciliar sobre o uso de drogas no Brasil: estudo envolvendo as 107 maiores cidades do país. 2002.São Paulo: Cromoste Gráfica e Editora

CASTRO, R. B. de. Eficácia, Eficiência e Efetividade na Administração Pública. $30^{\circ}$ Encontro da ANPAD. Salvador (BA). 2006. Disponível em: <http://www.anpad.org.br/enanpad/2006/dwn/enanpad2006-apsa1840.pdf> Acesso em 08/12/2015.

MICHELI, D; SILVA,E. A.; Adolescência, Uso e Abuso de Drogas: Uma Visão Integrativa. 2010. São Paulo: Fap. Unifesp Editora.

OLIVEIRA, E. B ; BITTENCOURT, L.P.;CARMO DO C.A. A importância da família na prevenção do uso de drogas entre crianças e adolescentes: papel materno. 2008. SMAD, Rev. Eletrônica Saúde Mental Álcool Drog.(Ed. port.) [online],vol.4,n.2 Disponível em: 〈http://www.pepsic.bvsalud.org/scielo.php > Acesso em $12 / 01 / 15$

PILLON, S.C, LUIS, M.A.V. Modelos explicativos para o uso de álcool e drogas e a prática da enfermagem. 2004. Revista Latino Americana de Enfermagem, v.12, n.4, p. 676-82.

TIBA, I. Juventude e Drogas: Anjos Caídos. 2007. São Paulo: Ed. Integrare.

SUDBRACK, M. F. O. E CESTARI, D.M. O modelo sistêmico e da educação para a saúde na prevenção da droga no contexto da escola: proposta do Projeto Piloto SENAD / MEC e UNB. 2005. Disponível em: <http://www.proceedings.scielo.br> Acesso em: 14 /02/15. 